\title{
The Impact Of Organizational Objectives On The Selection Of Defensive Marketing Strategies: Empirical Evidence From A Small Open Economy
}

Hassan Mounir El-Sady, Cairo University, Egypt

Mohamed Nassar, Gulf University for Science \& Technology, Kuwait Vasilya Sultanova, Australian College of Kuwait, Kuwait

Dia Mousa, National Bank of Kuwait, Kuwait

\begin{abstract}
Defensive Marketing Strategies (DMSs) do not receive enough attention as offensive or attacking marketing strategies in literature. This gap in the research constitutes a serious weakness in the marketing field. This paper aims to fill this gap in literature by conducting the first study to explore the determinants of the implemented DMSs in Kuwait. Empirically, this study examines the relationship between eight DMSs, demographics, and organizational objectives to define the most prevalent and appropriate DMSs to be deployed in the small open economy of Kuwait. Factor analysis and canonical correlation are used in this study to analyse the obtained data from surveyed board members, CEOs and executive managers of listed companies in the financial sector of Kuwait Stock Exchange (KSE). Results reveal a significant relationship between the eight DMSs and the two sets of identified variables in Kuwait context. Cost leadership strategy ranked the most effective defensive marketing strategy by respondents. Also, results show that organizational objectives are mostly affecting the choice of DMSs.
\end{abstract}

Keywords: Defensive Marketing Strategies in Kuwait; Organizational Objectives; Cost Leadership; Financial Sector

\section{INTRODUCTION}

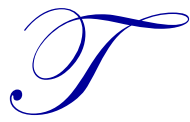

he small open economy of Kuwait enjoys several key economic strengths: it enjoys a high level of wealth, with a healthy net asset position, large and well-exploited oil reserves. On the other hand, the Kuwaiti economy depends mainly on oil revenues and dominated by the governmental sector. By the end of 2011, oil accounts for more than 50\% of the GDP, 90\% of export revenues, and $95 \%$ of government income in Kuwait. As Kuwait continues to look for ways to offset its dependence on oil revenues, the financial sector is playing an increasingly important role to achieve that.

The financial sector of Kuwaiti economy is well-developed with local and foreign banks at its core. The growing number of investment companies, mutual funds, real estate investment companies, and insurance firms in addition to the active stock exchange further contribute to the development of the Kuwaiti financial sector. The financial sector in Kuwait offers a wide variety of financial products and services and invests heavily in highly advanced technology and information systems to improve operational efficiency and enhance customer satisfaction.

Recently, the financial sector witnessed the highest growth rate of all sectors in the Kuwaiti economy. By the end of 2011, KSE's market capitalization worth $\$ 86.5$ bl., more than $57 \%$ of it contributed to financial sector and most of the new listed companies in KSE are related to the same sector. In 2005, foreign banks were permitted to operate in Kuwait, consequently number of banks in Kuwait increased by 82.5\% over the period of 2007-2010. 
Number of listed real estate investment companies experienced an increase of 193\% over the period of 2002-2011. Similarly, investment companies have been increased by almost $175 \%$ over the same period. Food \& Beverage, Industrial, Service, and non-Kuwaiti sectors did not witness high growth rate in market capitalization and listing in KSE as financial sector. The hyper growth rate of financial sector indicates severe competition for the existing companies with the new entrants, which requires appropriate selection of marketing strategies.

This paper aims to explore the drives of DMSs deployed by Kuwaiti companies from financial sector. It reviews literature on the subject of DMSs and examines the factors that affect the selection of DMSs in an attempt to find the most appropriate DMSs in the Kuwaiti financial sector context. It examines empirically the relationship between eight DMSs, namely; Business Intelligence (BI), Customer Service (CS), Cost Leadership (CL), Customer Complaint Management (CCM), Focus (FOC), Differentiation (DIFF), Aikido (AIKO) and Free Telephone Lines (FTL) and two sets of demographics and organizational objectives that define which DMS is more prevalent and appropriate to be deployed in Kuwait, as one of the emerging markets in the Gulf region with high growth rate. we hope that the findings and suggestions will provide value not only for financial sector, but also for Kuwaiti businesses in general, in defending their position, retaining customers, and finally maintaining and increasing market share and profit in a highly competitive small open economy.

This paper is organized as follows: First part of the paper is to introduce the main drives behind this study followed by review of literatures related to DMSs and organizational objectives in the second part. The methodology used is covered in the third part and the results are reported and discussed in the fourth part. The conclusion of the study is provided in part five followed by the references.

\section{LITERATURE REVIEW}

DMSs are relatively new to scholarly literature. Lotayif (2004) asserts that it was first used by Hauser and Shugan in 1983. Two and a half decades later, still little empirical or theoretical research has been done on the subject. Instead, researchers have continued to focus their attention on offensive or attacking marketing strategies, and as suggested by Roberts, Morrison and Nelson (2005), this gap in the research constitutes a serious weakness in the marketing field. As opposed to offensive marketing, which focuses on acquiring new customers, DMSs are concerned with retaining existing customers. Woodall (2004) reports that offensive marketing strategies are more costly than defensive marketing strategies. He claims that it's cheaper to keep existing customers than to get new ones. Erickson (1993) concedes that both defensive and offensive marketing strategies are necessary in a dynamic market environment, where organizations should strive to find a balance between retaining market share and fending off rivals' attacks while at the same time attracting new customers and expanding their market share. However, he argues that in a highly competitive environment, organisations should focus more on defensive strategies to retain customers.

Boyd (1996) consider DMSs as an approach that defends, protects and maintains market share, eliminates customer exit, and reduces brand switching. DMSs are viewed as customer-focused and aimed to retain customers by Woodall (2004) and Zeithaml et al. (2006). Several authors refer to limiting brand switching and customer exits by keeping the customer satisfied and so building loyalty as one of the most effective DMSs. Boyd (1996) focuses on after-sale service to existing customers to nurture brand loyalty so as to beat the competition, while Makhija (2008) asserts that defensive marketing is equal to relationship marketing that is retaining customers through building strong and lasting relationships with them. Roberts, Morrison, and Nelson (2005) suggest four generic strategic defence approaches: positive, negative, inertial and retarding strategies. Kotler and Singh (1981) use military warfare tactics and principles in discussing defensive marketing strategies. They list six defensive marketing strategies as following: position defence, flanking defence, pre-emptive defensive, counteroffensive defence, mobile defence and contraction defence.

Brackett (2001) defines Business Intelligence as a set of concepts, methods, and processes that enhance business decisions by utilising information from many sources to develop a precise understanding of the business dynamics. Davenport (2005) describes it as a set of information technology functions that help companies make decisions. Ranjan (2008) argues that in today's competitive and dynamic business world, BI is a deciding factor between survival and bankruptcy. Hill and Scott (2004) argue that the more companies know about their customers, 
the better they can anticipate their needs and satisfy them. Similarly, Clark and Montgomery (1999) propose that the ability of an incumbent to predict its competitor's responses will positively influence its profitability. Ranjan (2008) indicates that BI helps organisations to understand, transfer and shape data to make the right decisions, facilitate scrutiny of different operational aspects of the business, identify new revenue tracks and exclude others, and to save on costs.

Lymperopoulos et al. (2006) assert that customer service, as a major DMS, is the most important factor influencing a customer's choice of bank. Shafie et al. (2004) support this view, arguing that financial services are generally an undifferentiated product and providers should therefore improve their service quality in order to distinguish themselves from their rivals. While Zeithaml et al. (2006) view high quality customer service as fundamental to an organisation's profitability and survival.

Fornell and Wernerfelt (1988) argue that customer complaint management, as a DMS fosters trust and increases loyalty among customers. Zeithaml et al. (2006) indicates that customer retention is in itself a relatively cheap way to make profits, while acquiring new ones is five times more costly than retaining old ones. George and Hedge (2004) found that it is vital for companies to have effective complaints handling procedures and well-trained staff who are able to deal effectively with irate customers. As a form of customer feedback, complaints are very important tools in getting to know customers' expectations. Sense (1993) mentioned that customer complaints provide valuable feedback and can be useful sources of information and quality control, as well as for generating new beneficial ideas. Kau and Serene (1995) articulate the relationship between complaint behaviour and some demographic variables. They found that women tend to complain more and more likely to spread bad word of mouth if their complaints are not handled properly. These findings are contradicted by Manikas and Shea (1997) who found that men complain more than women. Jacoby and Jaccard (1981) found that the higher the customer's education, the more she/he will complain, while Heung and Lam (2003) add that complainants tend to be correlated with higher income.

Allen et al. (2007) suggest that cost leadership may be achieved through leveraging economies of scale, innovation, re-engineering activities, and learning curve benefits. In other words, CL can be described as a strategy that companies follow where they provide lower cost products and services than their competitors. It is claimed by Allen et al. (2007) that cost advantage comes from propriety technology and good access to raw materials. It is argued that differentiation may be achieved through design, technology, customer service, brand image, and/or special features. In financial sector, differentiation may be achieved through their distribution systems. Allen et al. (2007) argues that focus as a DMS is actually more suitable where the target market cannot be appropriately served by rivals who focus on larger, more generalised markets. Debruyne and Reibstein (2004) found that Focus (FOC) strategies are used successfully in the brokerage industry, while Power and Hahn (2004) found that banks that apply differentiation and focus strategies post above average results, whereas those who follow cost leadership ones realise superior performance over their rivals. When used defensively; cost leadership, differentiation and focus take the industry structure as a given and try to position the organisation to match both its strengths and weaknesses to this industry structure.

Cotter et al. (1997) describes the DMS named Aikido as a reactive self-defence strategy. It can be explained as a method of resistance where an organisation is able to anticipate an opponent's attack in order to redirect it, consequently achieve positive outcomes. Boyd (1996) argues that free telephone lines as a DMS have two major functions: (1) inbound (including customer care, complaints, up-selling lines and information dissemination) and (2) outbound (including market research, telemarketing and post purchase satisfaction. As such, they provide valuable feedback and are vital for nurturing strong customer relationships.

Kotler et al. (2005) argues that demographics variables, such as: density, size, age, race, position have a great influence on companies, their customers, and the way they do business as well as relating to their customers. This argument was supported by Zimmerer et al. (2007) who evidenced that organizations that are able to spot and proactively react to demographic trends by altering their strategies accordingly will gain a competitive advantage over their rivals, while those who fail to do so face the threat of becoming competitively obsolete. 
Zimmerer et al. (2007) clarifies that organisational objectives as specific performance targets usually addressing broad areas, such as productivity, profitability and growth, while Wheelen and Hunger (2006) focus on narrower objectives, such as increasing shareholder wealth, increasing efficiency, enhancing reputations, being the market leader, being the technological leader and contributing to both employees and society. Wheelen and Hunger (2006) indicated that there is a significant relation between organizational objectives and the selection of marketing strategy. They argue that organizational objectives determine the shape of an inclusive strategic master plan that states how an organisation will achieve and accomplish its mission and objectives. Accordingly, the selection of any defensive marketing strategy should be based on the organisation's primary objectives.

\section{HYPOTHESES AND METHODOLOGY}

To explore which DMSs are most applicable to the Kuwaiti financial sector and to identify the organizational objectives that influence the selection of these DMSs, this paper investigates the patterns of relationships between eight DMSs and demographic variables and organizational objectives. In order to meet these intents, two major questions followed by two minor questions were formulated. The first major questions to be answered by this research: "Is there a relationship between the eight DMSs demographic variables?" While the second question, "Is there a relationship between the eight DMSs and organizational objectives?" These questions were followed by two minor questions: (1) "Which DMS(s) is/are most applied in the Kuwaiti financial services sector?" and "Which organizational objective(s) has/have more effect on the adaptation of a given DMS in the Kuwaiti financial sector?" Based on hypotheses used by Lotayif (2004), this research tests for the following two hypotheses:

$\mathbf{H}_{1}$ : There is a significant relationship between the eight chosen DMSs and respondents' demographic variables.

$\mathbf{H}_{2}$ : There is a significant relationship between the eight chosen DMSs and organisational objectives.

Two sets of variables, dependent and independent, were used in the study. The eight DMSs featured in this study were considered dependent variables: (1) BI, (2) CS, (3) AIKO, (4) CL, (5) CCM, (6) FOC, (7) DIFF, and (8) FTL. The independent variables of this study that thought to guidance the selection of DMSs are divided into two groups; respondents' demographics and organisational objectives. Respondents' demographics include respondents: (1) Age, (2) Gender, (3) Education, (4) Position, and (5) Experiences. Organisational objectives include: (1) Increase Market Share (IMS), (2) Maintain Current Market Share (MCMS), (3) Increase Profit (IP), (4) Increase Customer Satisfaction (ICS), and (5) Increase Customers' Loyalty (ICL).

We applied two statistical techniques to analyse the obtained data. First, Factor Analysis (FA) was conducted to judge the importance of each DMS. Second, Canonical Correlation Analysis (CCA) was conducted as a multivariate technique to evaluate the relationship between non-metric dependent and independent variables, thus enabling us to investigate the relationship between two sets of variables. CCA was performed on multiple dependent and independent variables. Formula (1) provides the general form of Canonical Correlation technique:

$\beta_{1} Y_{1}+\beta_{2} Y_{2}+\beta_{3} Y_{3}+\ldots+\beta_{n} Y_{n}=\alpha_{1} X_{1}+\alpha_{2} X_{2}+\alpha_{3} X_{3}+\ldots \alpha_{n} X_{n}$

Where:

Y's represent DMSs as dependent variables,

X's represent Demographic and Organizational Objectives as independent variables,

$\beta_{1}$ to $\beta_{\mathrm{n}} \& \alpha_{1}$ to $\alpha_{\mathrm{n}}$ represent the effect magnitude, and

$\mathrm{P}$-value $<0.05$ indicates a significant relationship.

On the other hand, the qualitative data were analysed in comparison with both the literature and the findings of the quantitative data analysis. 


\section{RESEARCH POPULATION AND SAMPLING}

In the context of the Kuwaiti listed companies in the financial sector of KSE, the target population of the research survey included 356 board members, the chief executive officers and executive managers of banks, investment companies, and financial intermediaries. Copies of the research survey were sent to all targeted participants, hence there was no need to sample. In addition, eight expert participants were randomly selected for structured interviews: three economic analysts from the Kuwaiti media, one board member of an unlisted investment company, two managers from KSE, one economic researcher, and one marketing professional. The interview questions were extracted from the questionnaire and contain same themes.

Since this study is the first to examine the use of DMSs in Kuwait and the GCC region, we did not find any secondary data that can help in conducting this study. Therefore, we adopted a structured survey similar to Lotayif (2004) to gather primary data from Kuwaiti managers from financial sector in their use of DMSs. Our structured survey is consistent with the literature for the validity of the comparison of the results with other countries. The survey was conducted mainly by means of a multi-part questionnaire. It contains close-ended questions for the ease of completion and analysis. The questionnaire contains two parts. First part is to collect data about Respondent's demographic, including age, educational level, position, experience, organisation's experience, and number of staff. Second part is to question the organisational objectives including; increasing market-share, sustaining current market-share, raising profit, and enhancing customer satisfaction as well as loyalty.

Eight structured interviews were conducted to enhance the quantitative findings of the questionnaire. The interview questions were extracted from the questionnaire and contain the same three themes: DMSs, demographic variables, and organizational objectives. Questionnaires were presented in English and Arabic, noting that the Arabic version was a translation from the English original. Copies were distributed by hand to all participants, with follow-up phone calls to ensure responses. Three 356 questionnaires were sent out, 212 questionnaires were returned with $60 \%$ response rate. The usable questionnaires count for 176 with usable response rate of $83 \%$. In comparison with the response rates for questionnaires in literature, our response rate is above the international practices.

\section{RESULTS}

\section{Reliability}

The extent to which the research concepts were correctly defined in the measures was of major consideration. Before distributing questionnaires to participants, they were informally tested on a sample of twentyfive randomly selected senior managers working in the financial sector to assess the validity and the effectiveness of the questions. Testing the validity and effectiveness of the questions by Cronbach's Alpha, the sets of questioned variables assumed to influence the selection of DMSs by Kuwaiti firms from financial sector has $98.2 \%$ reliability, which is acceptable by statistical standards.

\section{Analysis of Descriptive Statistics}

Panel (A) of table (1) shows that: $33.5 \%$ of respondents were aged between 35 and 45 years, which is an accurate reflection of the wider Kuwaiti population. Panel (B) of the same table reveals that only $10.8 \%$ of the surveyed population were females, while $89.2 \%$ were males. This result is also consistent with the fact that Kuwaiti work force is male-dominated, even though there are more women than men in the population at large. Panel (C) of table (1) indicates that only $56.8 \%$ of board members, CEOs and executive managers hold university degrees, with a mere $4.5 \%$ holding Ph.D. degree, and fully $9 \%$ of them having no tertiary qualification at all. However, this can be attributed to the fact that most Kuwaiti companies are family businesses where personal connections play a central role in business management. Panel (D) of table (1) reveals that $38.1 \%$ of respondents were board members, while $61.9 \%$ were CEOs and executive managers, while Panel (E) of the same table shows that $54 \%$ of respondents had between five and ten years of experience in their position. Again, this can be ascribed to the nature of Kuwaiti businesses, where family members accede to the high positions within a relatively short period. 
Table 1: Demographics Descriptive Statistics:

\begin{tabular}{|c|c|c|c|c|}
\hline \multicolumn{5}{|c|}{ Panel A: Age Distribution } \\
\hline & Frequency & $\%$ & Valid \% & Cumulative $\%$ \\
\hline From $25 \leq 35$ & 36 & 20.5 & 20.5 & 20.5 \\
\hline From over $35 \leq 45$ & 59 & 33.5 & 33.5 & 54.0 \\
\hline From over $45 \leq 55$ & 51 & 29.0 & 29.0 & 83.0 \\
\hline From over $55 \leq 65$ & 24 & 13.6 & 13.6 & 96.6 \\
\hline Over 65 & 6 & 3.4 & 3.4 & 100.0 \\
\hline Total & 176 & 100.0 & 100.0 & \\
\hline \multicolumn{5}{|c|}{ Panel B: Gender Distribution } \\
\hline & Frequency & $\%$ & Valid \% & Cumulative $\%$ \\
\hline Male & 157 & 89.2 & 89.2 & 89.2 \\
\hline Female & 19 & 10.8 & 10.8 & 100.0 \\
\hline Total & 176 & 100.0 & 100.0 & \\
\hline \multicolumn{5}{|c|}{ Panel C: Education Distribution } \\
\hline & Frequency & $\%$ & Valid \% & Cumulative $\%$ \\
\hline Non University Degree & 16 & 9.1 & 9.1 & 9.1 \\
\hline University Degree & 100 & 56.8 & 56.8 & 65.9 \\
\hline Master Degree & 52 & 29.5 & 29.5 & 95.5 \\
\hline Ph.D. Degree & 8 & 4.5 & 4.5 & 100.0 \\
\hline Total & 176 & 100.0 & 100.0 & \\
\hline \multicolumn{5}{|c|}{ Panel D: Position Distribution } \\
\hline & Frequency & $\%$ & Valid \% & Cumulative $\%$ \\
\hline Board Member & 67 & 38.1 & 38.1 & 38.1 \\
\hline CEOs \& Executive Manager & 109 & 61.9 & 61.9 & 100.0 \\
\hline Total & 176 & 100.0 & 100.0 & \\
\hline \multicolumn{5}{|c|}{ Panel E: Years of Experience Distribution } \\
\hline & Frequency & $\%$ & Valid \% & Cumulative $\%$ \\
\hline From $2 \leq 5$ & 24 & 13.6 & 13.6 & 13.6 \\
\hline From over $5 \leq 10$ & 95 & 54.0 & 54.0 & 67.6 \\
\hline From over $10 \leq 15$ & 40 & 22.7 & 22.7 & 90.3 \\
\hline Over 15 Years & 17 & 9.7 & 9.7 & 100.0 \\
\hline Total & 176 & 100.0 & 100.0 & \\
\hline
\end{tabular}

\section{Factor Analysis}

Factor Analysis (FA), as exploratory method is conducted to explain and judge the significance of each DMS within the minds of the target population using the rotated component matrix technique. It is carried out and complemented on the correlation matrix of the observed variables, with a "factor" being the mean of the original variables. In addition, the aim of using FA technique in this study is to assist with data interpretation, in the hope of identifying and recognising every factor as representing a precise theoretical factor.

Table (2) illustrates the correlation among the respondents' responses and the importance attached to each DMS. Results shown in table (2) explores that cost leadership outline $26.3 \%$ of applied DMSs by Kuwaiti companies providing financial services, followed by customer service management (15.2\%), focus (13.5\%), customer complaint management (12.9\%), business intelligence (11.1\%), differentiation (8.1\%), aikido (7.3\%), and lastly free telephone lines (5.6\%). These results advise Kuwaiti financial services providers to apply cost leadership as their primary DMS in response to threats from new entrants.

The results of the structured interviews supported these findings. Five out of eight interviewees agreed that cost leadership and customer service are the most vital defensive strategies; while three out of eight viewed customer complaint management is very important as well. Moreover, interviewees emphasised the importance of segmentation in order to better serve individual segments and thus enhance service quality. Only one interviewee was of the opinion that the best defensive strategy is an offensive strategy. 
Table 2: Factor Analysis Results (Importance of Each DMS)

\begin{tabular}{lccc}
\hline Defensive Marketing Strategies & Eigen-value & Extracted Variance & Factor Loading \\
\hline Cost Leadership (CL) & 2.105 & $26.315 \%$ & 0.982 \\
Customer Service (CS) & 1.218 & $15.221 \%$ & 0.986 \\
Focus (FOC) & 1.081 & $13.508 \%$ & 0.986 \\
Customer Complaint Management (CCM) & 1.033 & $12.918 \%$ & 0.983 \\
Business Intelligence (BI) & 0.889 & $11.111 \%$ & 0.970 \\
Differentiation (DIFF) & 0.646 & $8.079 \%$ & 0.964 \\
Aikido (AIKO) & 0.580 & $7.256 \%$ & 0.961 \\
Free Telephone Line (FTL) & 0.447 & $5.592 \%$ & 0.955 \\
\hline
\end{tabular}

Our results show a strong correlation with those mentioned in the literature. The majority of respondents agreed with Power and Hahn (2004) that banks follow cost leadership strategy realise superior performance, while those follow differentiation and focus strategies also achieve above average performances. In addition, interviewees also agreed with Zeithaml et al. (2006) and Lymperopoulos et al. (2006), in stating that high quality service is the key to any organisation's success, because it confers a competitive advantage.

\section{Canonical Correlations}

The Relationship between Demographic Variables and Defensive Marketing Strategies:-

Table (3) shows the estimated correlation between each set of canonical variables, where variables have first been standardized by subtracting their means and dividing by their standard deviations. Since three of the Pvalues are less than 0.05 , those sets have statistically significant correlations at the $95.0 \%$ confidence level. In addition, table (3) shows a significant relationship between the demographic variables and the eight defensive marketing strategies where p-value of $0.0000,0.0045$ and 0.0487 is less than 0.05 as indicated in the first three functions in table (3), and Canonical correlation of 0.526 higher than 0.50 , as indicated in the first function of the same table. However, the remaining four variables will be eliminated since they are insignificant. The selected function's Eigenvalue of 0.276 represents the amount of shared variance in the defensive marketing strategies that is account for by the demographic variables. In other words, the Eigen-value of 0.276 of the selected function indicates that the demographic variables explain 0.276 of the selection of DMSs to be adopted by Kuwaiti financial sector.

Table 3: Canonical Correlations between Demographic Variables and DMSs.

\begin{tabular}{cccccc}
\hline Function Number & Eigenvalue & Canonical Correlation & Chi-Squared & D.F. & P- Value \\
\hline $\mathbf{1}$ & $\mathbf{0 . 2 6 5}$ & $\mathbf{0 . 5 2 6}$ & $\mathbf{1 2 3 . 7 5}$ & $\mathbf{5 6}$ & $\mathbf{0 . 0 0 0 0}$ \\
$\mathbf{2}$ & $\mathbf{0 . 1 4 3}$ & $\mathbf{0 . 3 7 9}$ & $\mathbf{6 9 . 7 6}$ & $\mathbf{4 2}$ & $\mathbf{0 . 0 0 4 5}$ \\
$\mathbf{3}$ & $\mathbf{0 . 1 0 9}$ & $\mathbf{0 . 3 3 1}$ & 24.53 & $\mathbf{3 0}$ & $\mathbf{0 . 0 4 8 7}$ \\
4 & 0.079 & 0.282 & 10.70 & 20 & 0.2200 \\
5 & 0.043 & 0.207 & 12 & 0.5550 \\
\hline
\end{tabular}

Although functions number (2) and (3) are also significant, given their p-value of 0.0045 and 0.0487 respectively, they could not be included in the analysis as their canonical correlation is less than 0.5 and the use of the first function to explain the investigated relationship rules out the other functions with less canonical correlation.

Based on the results shown in panel (A) of table (4) reporting the magnitude of canonical correlations of DMSs and reported magnitude of canonical correlations of demographic variables in panel (B) of table (4), the relationship between the eight DMSs and demographic variable can be expressed as followed by formula (2):-

$\{-0.408 \mathrm{BI}+0.529 \mathrm{CS}-0.107 \mathrm{AIKO}+0.367 \mathrm{CL}-0.147 \mathrm{CCM}+0.289 \mathrm{FOC}+0.011 \mathrm{DIFF}+0.444 \mathrm{FTL}\}=\{-0.550$ Age +0.624 Gender -0.141 Education +0.231 Position + 0.486 Experience

All dependent and independent variables expressed in formula (2) are based on function number (1) of table (3) which indicates a strong and significant relationship between DMSs tested in this study and demographic variables. All results are significant at $99 \%$ level with $P$-Value less than 0.05 . On the independent variables side of formula (2) and as reported in panel (B) of table (4), gender has the highest positive effect on the chosen DMSs with 
magnitude of $62.42 \%$, followed by respondents' experience with magnitude of $48.75 \%$ and respondents' positions with magnitude of $23.04 \%$. Also, panel (B) of table (4) shows that age and education levels of respondents have a strong and negative impact on the selected DMSs negative magnitude of $55 \%$ and $14.1 \%$, respectively.

On the dependent variables side of formula (2), panel (A) of table (4) reports that CS strategy is the best DMS to be deployed by Kuwaiti financial sector with the highest positive magnitude of $52.86 \%$, followed by FTL, CL, and FOC strategies with magnitude of $44.36 \%, 36.72 \%$, and $28.99 \%$ respectively. With positive magnitude of $1 \%$, respondent from surveyed companies indicated that DIFF strategy is the least DMS to be deployed by Kuwaiti financial sector. These results can be explained based on the strong heard behaviour of Kuwait market, which duplicates any new product or service leaving no likelihood for differentiation. Results reported in formula (2) reveals that BI, CCM and AIKO strategies, as reported in panel (A) of table (4) have negative magnitudes of $40.76 \%,-14.72 \%$ and $-10.75 \%$, respectively on selected DMSs to be adopted by financial sector in Kuwait. These can be explained by the fact that, in Kuwait most of the companies are family business from large to small caps including banks. Therefore, there is no need for business intelligence or even customer complaint management.

Table 4: Canonical Correlations Results.

\begin{tabular}{|c|c|c|c|c|c|}
\hline \multicolumn{6}{|c|}{ Panel (A): Canonical Correlations Matrix for the Eight Defensive Marketing Strategies. } \\
\hline Strategies & Function \# 1 & Function \# 2 & Function \# 3 & Function \# 4 & Function \# 5 \\
\hline BI & -0.408 & -0.530 & 0.301 & 0.474 & 0.013 \\
\hline $\mathrm{CS}$ & 0.529 & -0.063 & 0.348 & -0.164 & -0.297 \\
\hline AIKO & -0.107 & 0.050 & 0.418 & -0.841 & 0.216 \\
\hline CL & 0.367 & -0.684 & -0.122 & 0.029 & -0.398 \\
\hline $\mathrm{CCM}$ & -0.147 & 0.563 & 0.305 & 0.289 & -0.528 \\
\hline FOC & 0.289 & 0.176 & -0.824 & -0.065 & 0.127 \\
\hline DIFF & 0.011 & 0.081 & -0.228 & -0.261 & -0.576 \\
\hline FTL & 0.444 & 0.290 & 0.410 & 0.433 & 0.502 \\
\hline \multicolumn{6}{|c|}{ Panel (B): Canonical Correlations Matrix for Demographic Variables. } \\
\hline Variables & Function \# 1 & Function \# 2 & Function \# 3 & Function \# 4 & Function \# 5 \\
\hline Age & -0.550 & 0.275 & 0.316 & -0.442 & -0.415 \\
\hline Gender & 0.624 & 0.586 & 0.201 & -0.096 & 0.078 \\
\hline Education & -0.141 & 0.124 & -0.698 & -0.065 & 0.548 \\
\hline Position & 0.231 & 0.041 & -0.630 & -0.289 & -0.605 \\
\hline Experience & 0.486 & -0.950 & -0.016 & -0.054 & 0.148 \\
\hline
\end{tabular}

Also, all interviewees in the structured interviews agreed that demographic factors do affect the decision making around the selection of DMSs. They all consider age of the decision makers, their position in the company, their education level and experience are important. Interestingly, no interviewee considered gender as having any impact on the choice of DMS.

These findings support first hypotheses, indicating that there is a significant relationship between the eight chosen DMSs and respondents' demographic variables, and demographic variables have impacts on these DMSs. These results are compatible with those mentioned in the literature, where Zimmerer et al. (2007) found that companies that manage to spot the demographic trends obtain a competitive advantage in the market.

The Relationship between Organisational Objectives and Defensive Marketing Strategies:-

Based on the results reported in table (5), function number (1) indicates a strong and significant relationship between organisational objectives of the surveyed companies and the DMSs deployed by these companies. Function (1) of table (5) has a p-value of 0.0043 , which is less than 0.05 and canonical correlation of 0.523 , which is greater than 0.5. The selected function's Eigenvalue is 0.269 , which represent the extent to which independent variables influence or explain the behaviour of dependent variables. In other words, organizational objectives explain 0.269 of the selection of DMSs to be deployed by Kuwaiti companies from financial sector. All other functions reported in table (5) could not be included in the analysis as their $p$-value more than 0.05 and canonical correlation less than 0.5. 
Table 5: Canonical Correlations between Organisational Objectives and DMSs.

\begin{tabular}{cccccc}
\hline Function Number & Eigenvalue & Canonical Correlation & Chi-Squared & D.F. & P- Value \\
\hline $\mathbf{1}$ & $\mathbf{0 . 2 7 9}$ & $\mathbf{0 . 5 2 3}$ & $\mathbf{6 7 . 4 1}$ & $\mathbf{4 0}$ & $\mathbf{0 . 0 0 4 3}$ \\
2 & 0.120 & 0.346 & 34.35 & 28 & 0.1897 \\
3 & 0.059 & 0.243 & 12.92 & 18 & 0.7963 \\
4 & 0.012 & 0.109 & 2.713 & 10 & 0.9874 \\
5 & 0.004 & 0.065 & 0.703 & 4 & 0.9510 \\
\hline
\end{tabular}

Based on the magnitude of canonical variables of DMSs and the magnitude of canonical variables for organizational objectives reported in panel (A) and (B) of table (6), the relationship between DMSs and organizational objectives can be expressed by formula (3):-

$\{-0.578 \mathrm{BI}+0.039 \mathrm{CS}+0.358 \mathrm{AIKO}+0.482 \mathrm{CL}-0.439 \mathrm{CCM}-0.330 \mathrm{FOC}+0.013 \mathrm{DIFF}+0.317 \mathrm{FTL}\}=\{+0.589$

IMS +0.401 MCMS -0.365 IP -0.246 ICS +0.543 ICL\}

On the organizational objectives side of the canonical formula (3), and as reported in panel (B) of table (6), IMS has the highest positive effect on the chosen DMSs with magnitude of $58.9 \%$, followed by ICL and MCMS, with magnitude of $54.3 \%, 40.1 \%$, respectively. Also, panel (B) of table (6) shows that the IP and ICS have a negative magnitude of $36.5 \%$ and $24.6 \%$, respectively, on the selected DMSs deployed by Kuwaiti financial sector.

On the DMSs side of the Canonical formula (3), CL accounts for the highest positive magnitude of $48.2 \%$, followed by AKIO and FTL with positive magnitude of $35.8 \%$ and $31.7 \%$ respectively, while CS and DIFF has less positive magnitude of $3.9 \%$ and $1.3 \%$ respectively. BI, CCM, and FOC strategies show negative magnitudes of $57.8 \%,-43.9 \%$ and $-33 \%$, respectively.

In conclusion, formula (3) indicate that companies from Kuwaiti financial sector focus on cost leadership, aikido, and free telephone line as the DMSs that can lead them to increase market share, increase customers' loyalty and maintain current market share. While results shown in formula (3) show that increase profit and increase customer satisfactions have negative effect on the selection of DMSs to be deployed Kuwaiti companies providing financial services.

Table 6: Canonical Correlations Results - Organisational Objectives.

\begin{tabular}{lccccc}
\hline \multicolumn{7}{c}{ Panel (A): Canonical Correlations Matrix for the Eight Defensive Marketing Strategies. } \\
\hline Strategies & Function \# & Function \# 2 & Function \# 3 & Function \# 4 & Function \# 5 \\
\hline BI & $\mathbf{- 0 . 5 7 8}$ & 0.238 & -0.430 & -0.311 & 0.552 \\
CS & $\mathbf{0 . 0 3 9}$ & 0.285 & 0.108 & -0.358 & 0.022 \\
AIKO & $\mathbf{0 . 3 5 8}$ & -0.413 & -0.158 & 0.627 & -0.003 \\
CL & $\mathbf{0 . 4 8 2}$ & -0.402 & -0.283 & -0.554 & -0.731 \\
CCM & $\mathbf{- 0 . 4 3 9}$ & -0.073 & -0.485 & 0.492 & -0.424 \\
FOC & $\mathbf{- 0 . 3 3 0}$ & -0.696 & 0.581 & -0.107 & 0.497 \\
DIFF & $\mathbf{0 . 0 1 3}$ & -0.043 & 0.584 & 0.281 & -0.204 \\
FTL & $\mathbf{0 . 3 1 7}$ & 0.096 & -0.347 & 0.236 & 0.768 \\
\hline \multicolumn{7}{l}{} & Panel $(\mathbf{B}) \mathbf{C a n o n i c a l ~ C o r r e l a t i o n s ~ M a t r i x ~ f o r ~}$ & Organisational Objectives Variables. & \\
Objectives & Function \# 1 & Function \# 2 & Function \# 3 & Function \# 4 & Function \# 5 \\
\hline IMS & $\mathbf{0 . 5 8 9}$ & -0.056 & -0.010 & -0.203 & -0.960 \\
MCMS & $\mathbf{0 . 4 0 1}$ & -0.938 & -0.041 & -0.022 & 0.272 \\
IP & $\mathbf{- 0 . 3 6 5}$ & -0.277 & 0.640 & -0.652 & 0.093 \\
ICS & $\mathbf{- 0 . 2 4 6}$ & 0.390 & -0.728 & -0.715 & 0.276 \\
ICL & $\mathbf{0 . 5 4 3}$ & 0.431 & 0.533 & 0.267 & 0.709 \\
\hline
\end{tabular}

Seven of the eight interviewees selected for structured interview agreed that there is a relation between organizational objectives and the implemented DMS, confirming our findings reported in panels (A) and (B) of table (6). Moreover, they see that increasing profit, increasing and maintaining market share and increasing customers' satisfaction and loyalty are all important goals. However, only one expert argues that profit is the only objectives that every organization is looking for. As a result, we can conclude that there is a significant relationship between organization's objectives and the selection of defensive marketing strategies. This findings is similar to Wheelen 
and Hunger (2005) and Best (2000). They indicated that objectives are determining plans and strategies, where the selected strategies by firms must draw the path to meet its objectives. Thus, hypotheses two has been supported.

\section{CONCLUSION}

While research into DMS has been rather limited in the past, there appears to be growing interest in the field, due to increased awareness of the importance of defensive positioning in the context of accelerating global competition. Instead of trying to win more market share, incumbents are focusing more and more on retaining and defending their positions and market share. This research aimed at alerting the Kuwaiti companies to the importance of DMS and suggesting how they may protect their positions in an increasingly competitive environment, given that that Kuwait is striving to establish itself as a regional financial hub.

Results of the analysis of the research survey showed conclusively that there is a relationship between the eight DMSs and the two sets of variables in question. Factor analysis of the quantitative data showed that cost leadership is the most applicable DMS for the Kuwaiti financial sector (26.3\%). Alternatively, canonical correlation revealed that there is a significant relationship between the selection of DMSs and organizational objectives, thus supporting hypotheses 1 and 2.

Cost leadership strategy ranked the most applicable defensive strategy in the Kuwaiti financial sector and new entrants' competitive advantages and incumbent organization's business objectives are mostly affecting the choice of DMSs to be deployed in Kuwaiti financial sector. Cost leadership strategy requires efficient resource allocation compared to rivals and tight control on all costs. To be a cost leader, banks and financial services companies may need to increase deposit rates or return and decrease financial services interests or/and commissions.

Results suggest that, although demographics have a significant role to play, decision makers and strategic planners in the Kuwait should pay particular attention to their own organizational objectives. They further suggest that cost leadership is the most useful DMS, since it is difficult to differentiate financial products and services. Banks, investment companies, and financial intermediaries should therefore continue to reduce their own costs and translate that into more favorable prices, lower interest rates on loans, and lower commissions and fees. Customer service also plays a vital role in nurturing a loyal customer base and resisting switching. Banks and investment companies should also do accurate customer segmentation to enable them to customise products to fulfil customers' needs, expectations and preferences. This should increase customer satisfaction and loyalty and hence profitability. However, differentiation is difficult to employ in the service industry, because services can be easily imitated.

This study has a significant implication as it offers to identify suitable DMSs to be deployed by Kuwaiti companies. Results suggest that decision makers and strategic planners in Kuwait are constantly required to pay particular attention to their own organisational objectives. Future studies would benefit from including frontline staffs who communicate directly and closely with customers and who have a better understanding of their needs and expectations. It would also be useful for future research to investigate DMSs in other Kuwaiti sectors, especially telecommunications and logistics. There is also room for investigating other variables than those examined here, for example the impact of economic and political considerations on the selection of DMSs.

\section{AUTHOR INFORMATION}

Dr. Hassan Mounir El-Sady is an associate professor of finance in the college of commerce at Cairo University. $\mathrm{He}$ is currently the director of continues and professional education center at Gulf University for Science \& Technology, Kuwait and the Economic Advisor of Kuwait Stock Exchange. E-mail: Elsady.h@gust.edu.kw (Corresponding author)

Dr. Mohamed Ahmed Nassar is an assistant professor of management and marketing in the college of business administration at Gulf University for Science \& Technology, Kuwait. E-mail: Nassar.m@gust.edu.kw

Vasilya Sultanova is a Ph.D. candidate and lecturer of management and marketing at the Australian College of Kuwait. E-mail: V.sultanova@ack.edu.kw 
Dia Mousa is the Quality Assurance Team Leader at the National Bank of Kuwait. E-mail: Dia221975@yahoo.com

\section{REFERENCES}

1. Allen, R., Helms, M., Takeda, M. and White, C. (2007). Porter's Generic Strategies: An Exploratory Study of Their Use In Japan. Journal of Business Strategies, 24(1) 69-90.

2. Boyd, E. (1996). Defensive Marketing's use of Post-Purchase Telecommunications to Create Competitive Advantages: A Strategic Analysis. Journal of Consumer Marketing, (1) 26-34.

3. Brackett, M.H. (2001). Business intelligence value chain, DM Review, 1-6.

4. Clark, B. and Montgomery, D. (1999). Managerial Identification of Competitors. Journal of Marketing, 63(July) 67-83.

5. Cotter, M., Henley, J. and Pelham, A. (1997). The Philosophy and Practice of Aikido: Implications for Defensive Marketing. SAM Advanced Management Journal, 62(1), 14-19.

6. Davenport, T. (2005). The Coming Commoditization of Processes. Harvard Business Review, 83(6) 100108.

7. Debruyne, M. and Reibstein. D. (2004). Social contagion and income heterogeneity in new product diffusion: A meta-analytic test. Marketing Science, 23(4) 1-12.

8. Erickson, G. (1993). Offensive and Defensive Marketing: Closed-Loop Duopoly Strategies. Marketing Letters, 4(4) 285-295.

9. Fornell, C. and Wernerfelt, B. (1988). A Model for Customer Complaint Management. Marketing Science, 7(3) 287-298.

10. George, B. and Hegde, P. (2004). Employee attitude towards customers and customer care challenges in banks. The International Journal of Bank Marketing, 22(6) 390-406.

11. Heung, V. and Lam, T. (2003). Customer complaint behavior towards hotel restaurant services. International Journal of Contemporary Hospitality Management, 15(5) 283-289.

12. Hill, J. and Scott, T. (2004). A consideration of the roles of business intelligence and e-business in management and market decision making in knowledge based and high-tech start-ups, qualitative market research, International Journal, 7(1) 48-57.

13. Jacoby, J. and Jaccard, J. (1981). The sources, meanings and validity of consumer complaint behavior: a psychological analysis. Journal of Retailing, 57(3) 4-24.

14. Kotler, P. and Singh, R. (1981). Marketing warfare in the 1980s. The Journal of Business Strategy, 1(3) 3042.

15. Kotler, P., Wond, V., Saunders, J. and Armstrong, G. (2005). Principles of Marketing. United Kingdom: Prentice-Hall.

16. Kau, K. and Serene, D. (1995). Determinants of Consumer Complaint Behavior: A study of Singapore Consumers. Journal of International Consumer Marketing, 8(2) 59-76.

17. Lotayif, M. (2004). Factors that affect the selection of defensive marketing strategies: evidence from the Egyptian banking sector. Journal of American Academy of Business, 4(1/2) 152-158.

18. Lymperopoulos, C., Chaniotakis, I. and Soureli, M. (2006). The importance of service quality in bank selection for mortgage loans. Managing Service Quality, 16(4) 365-379.

19. Makhija, T. (2008). Retention marketing - the key to business performance. The Journal, 55-58.

20. Manikas, P. and Shea, L. (1997). Hotel complaint behavior and resolution: a content analysis. Journal of Travel Research, 36(2) 68-73.

21. Power, T. and Hahn, W. (2004). Critical competitive methods, generic strategies and firm performance. The International Journal of Bank Marketing, 22(1) 43-64.

22. Ranjan, J. (2008). Business justification with business intelligence. The Journal of Information and Knowledge Management Systems, 38(4) 461-475.

23. Roberts, J., Morrison, P. and Nelson, C. (2005). A Prelaunch Diffusion Model for Evaluating Market Defense Strategies. Marketing Science, 24(1) 150-164.

24. Sense, C. (1993). Complaints are Hidden Treasure. Journal for Quality and Participation, 16(5) 78-82.

25. Shafie, S., Azmi, W. and Haron, S. (2004). Adopting and Measuring Customer Service Quality in Islamic Banks: A Case Study of Bank Islam Malaysia Berhad. Journal of Muamalat and Islamic Finance Research, 1(1) 1-11. 
26. Wheelen, T. and Hunger, D. (2006). Strategic Management and Business Policy. USA: Pearson PrenticeHall.

27. Woodall, T. (2004). Why Marketers Don't Market: Rethinking Offensive and Defensive Archetypes. Journal of Marketing Management, (20) 559-576.

28. Zeithaml, V., Bitner, M. and Gremler, D. (2006). Service Marketing: Integrating Customer Focus Across the Firm. New York: McGraw Hill.

29. Zimmerer, T., Norman, S. and Dough, W. (2007). Essentials of Entrepreneurship and Small Business Management. USA: Pearson Prentice-Hall. 